\title{
Comparison of Parent-Child Interactions in Abusive and Control Families: An Observational Study
}

Jocelyn F. O. Stokes

West Virginia University

Follow this and additional works at: https://researchrepository.wvu.edu/etd

\section{Recommended Citation}

Stokes, Jocelyn F. O., "Comparison of Parent-Child Interactions in Abusive and Control Families: An Observational Study" (2011). Graduate Theses, Dissertations, and Problem Reports. 4797. https://researchrepository.wvu.edu/etd/4797

This Thesis is protected by copyright and/or related rights. It has been brought to you by the The Research Repository @ WVU with permission from the rights-holder(s). You are free to use this Thesis in any way that is permitted by the copyright and related rights legislation that applies to your use. For other uses you must obtain permission from the rights-holder(s) directly, unless additional rights are indicated by a Creative Commons license in the record and/ or on the work itself. This Thesis has been accepted for inclusion in WVU Graduate Theses, Dissertations, and Problem Reports collection by an authorized administrator of The Research Repository @ WVU. For more information, please contact researchrepository@mail.wvu.edu. 
Comparison of Parent-Child Interactions in Abusive and Control Families: An Observational Study

Jocelyn F. O. Stokes

Thesis submitted to the
Eberly College of Arts and Sciences
at West Virginia University
in partial fulfillment of the requirements
for the degree of
Master RI Science
in
Psychology

Cheryl B. McNeil, Ph.D., Chair Amy Gentzler, Ph.D.

Tracy Morris, Ph.D.

Department of Psychology

Morgantown, West Virginia

2011

Keywords: Child physical abuse, parent-child interactions

Copyright 2011 Jocelyn Stokes 


\begin{abstract}
Comparison of Parent-Child Interactions in Abusive and Control Families: An Observational Study
\end{abstract}

By Jocelyn F. O. Stokes

This study sought to identify differences in caregiver-child interactions between caregivers with and without prior reports of child physical abuse. Data for the abuse group were made available for secondary analyses by the National Archive for Child Abuse and Neglect via Cornell University. Data for the comparison group were collected for a previous study at West Virginia University. For both studies, caregiver-child dyads participated in a 5-minute, videotaped observation in a situation in which the parent had to exert moderate control over the child. Data that had been coded using the Dyadic Parent—Child Interaction Coding System (Eyberg, et al., 1994; Eyberg, et al., 2005) were compared in 70 caregiver-child dyads. Groups were similar with regard to child behavior, parent age, child gender, parental education level, caregiver marital status, and relation of parent to child. Analyses were conducted with both the sample of 70 dyads, in which children in the abuse group were older, and with a subsample of 41 dyads, in which all children were 4- to 5-years-old and significantly more caregivers in the abuse group were male. Race was considered in both sets of analyses. Results with both samples revealed that, over and above demographic differences, parents in the abuse group talked significantly more and, after additionally controlling for total talk, gave significantly less praise. These results inform parental fitness examinations, but observations should be examined within a broader assessment. Limitations of this study include comparison of two pre-existing samples with some procedural and sample differences. Future research should consider demographic differences when examining caregiver-child differences in abusive samples and attempt to include fathers. 


\section{Acknowledgement}

The data used in this publication were made available by the National Data Archive on Child Abuse and Neglect, Cornell University, Ithaca, NY, and have been used with permission. Data from Physical Abuse Treatment Outcome Project: Application of Parent-Child Interaction Therapy (PCIT) to Physically Abusive Parents were originally collected by Mark Chaffin. Funding for the project was provided by the U.S. Department of Health and Human Services, The Administration on Children, Youth and Families, Children’s Bureau, Office on Child Abuse and Neglect (Award Number: 90CA1633). The collector of the original data, the funder, NDACAN, Cornell University and their agents or employees bear no responsibility for the analyses or interpretations presented here. 
Table of Contents

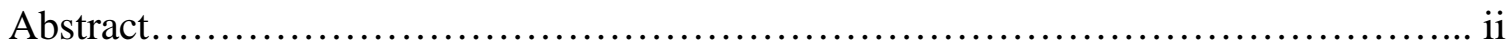

Acknowledgement...........................................................

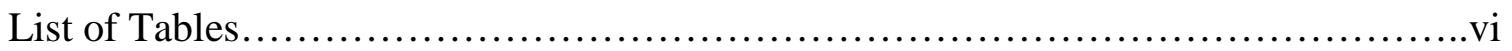

Chapter 1: Literature Review...................................................1

Observational Studies of Parent-Child Interactions in Child Abuse ...............3

Praise............................................................. 3

Commands.......................................................

Negative Talk..................................................10

Amount of Interaction........................................ 11

Summary..................................................... 11

Dyadic Parent-Child Interaction Coding System.......................... 13

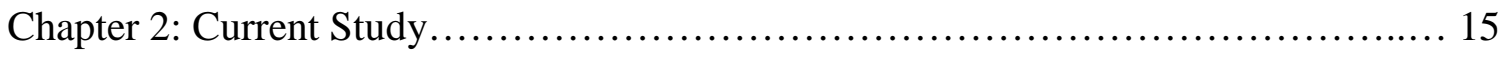

Hypotheses....................................................... 16

Chapter 3: Method....................................................... 16

Participants........................................................ 16

Abuse Group............................................... 16

Comparison Group........................................... 18

Measures............................................................... 20

Demographic Information................................... 20

Dyadic Parent-Child Interaction Coding System..................... 20

Chapter 4: Results...................................................... 22

Sample of 70 Caregiver-Child Dyads with Children Ages 3-7 Years........... 22 
Demographic information......................................... 23

Examination of demographic and child behavior differences.............. 23

Comparison of groups.................................................. 26

Total Talk................................................... 26

Praise...................................................... 26

Negative Talk............................................. 26

Commands.................................................... 27

Logistic Regression.............................................. 27

Sample of 41 Dyads with Children Ages 4-5 Years............................ 27

Demographic information.......................................... 27

Examination of demographic and child behavior differences............. 28

Comparison of groups............................................. 30

Total Talk................................................. 30

Praise........................................................... 31

Negative Talk............................................. 31

Commands...................................................... 31

Logistic Regression.............................................. 31

Chapter 5: Discussion.................................................... 32

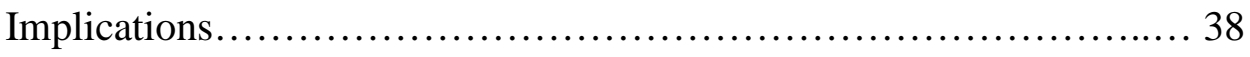

Limitations....................................................... 39

Future Directions............................................... 41

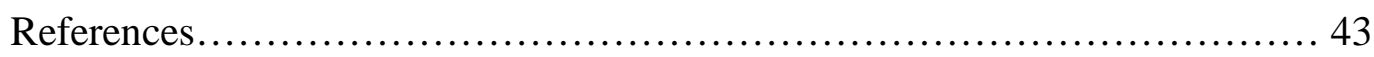

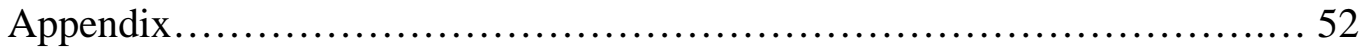


List of Tables

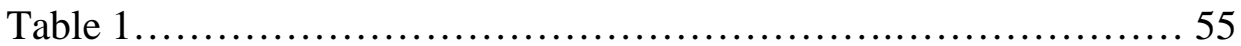

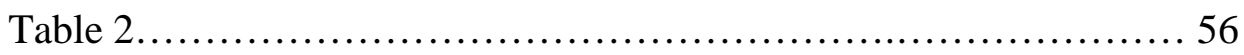

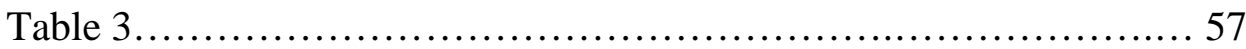

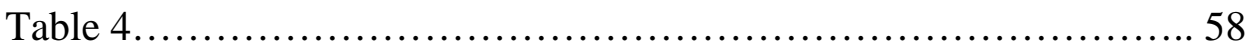

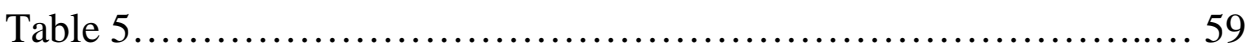

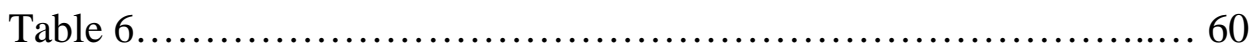

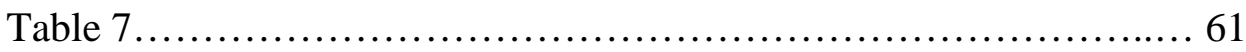

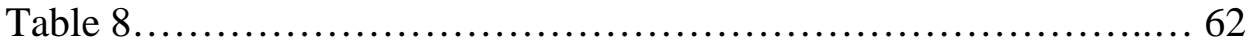

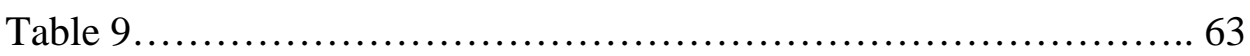

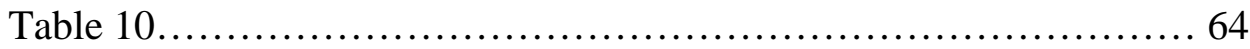

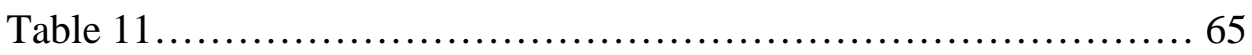

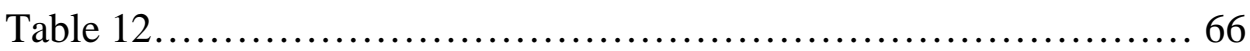




\section{Chapter 1: Literature Review}

Child abuse is a prevalent social problem in the United States and abroad that predicts numerous poor outcomes for the affected child's life and community. Federal law defines child abuse as any act or failure to act on the part of the caretaker that results in physical or emotional harm, injury, exploitation, or death of the child (Child Welfare Information Gateway, 2008). While state laws vary, most agree that physical abuse is the excessive use of corporal punishment, such as intentionally hitting, kicking, and burning a child (Child Welfare Information Gateway, 2008). In 2007, 794,000 children were victims of abuse. The majority of children was neglected (59\%), followed by physically abused (10.8\%), sexually abused (7.6\%), and emotionally or psychologically abused (4.2\%; U.S. Department of Health and Human Services, Administration on Children, Youth, and Families, 2009).

Child physical abuse is associated with a plethora of poor outcomes that can last into adulthood. Such outcomes include depression (Kaplan, Pelcovitz, Salzinger, Weiner, Mandel, Lesser, \& Labruna, 1998; Kaplow \& Widom, 2007; Reinherz, Paradis, Giaconia, Stashwick, \& Fitzmaurice, 2003), anxiety (Kaplow \& Widom, 2007), conduct disorder (Kaplan, et al., 1998; Kunitz, Levy, McCloskey, \& Gabriel, 1998; McCabe, Hough, Yeh, Lucchini, \& Hazen, 2005), substance abuse (Cohen, Mandarin, Murray, \& Gellman, 2006; Kaplan, et al., 1998; Min, Farkas, Minnes, \& Singer, 2007), low self-esteem (Kaufman \& Cicchetti, 1989), increased suicidality (Cohen, et al., 2006), post-traumatic stress disorder (Cohen, et al., 2006), and increased risk of HIV infection (Auslander, McMillen, Elze, Thompson, Johnson-Reid, \& Stiffman, 2002; Cohen, et al., 2006, Wilson \& Widom, 2008). Additionally, abuse can result in death. In 2007, 1,760 children 
died in association with their abuse or neglect, and $75.7 \%$ of these children were under the age of four (U.S. Department of Health and Human Services, Administration on Children, Youth and Families, 2009).

It is also important to note that child abuse and neglect occurs in all socioeconomic, ethnic, religious, racial, and cultural groups (U.S. Department of Health and Human Services, Administration on Children, Youth and Families, 2009). However, certain characteristics are associated with caregivers who engage in abuse. They often are single parents (Milner \& Chilamkurti, 1991), have low levels of social support, have substance abuse problems, have a high level of parental stress, and have a history of being abused as children (Belsky, 1993; Milner \& Chilamkurti, 1991; U.S. Department of Health and Human Services, Administration on Children, Youth and Families, 2009).

Additionally, family life often is unstructured, involves domestic violence (U.S. Department of Health and Human Services, Administration on Children, Youth and Families, 2009), and is stressful (Milner \& Chilamkurti, 1991; U.S. Department of Health and Human Services, Administration on Children, Youth and Families, 2009). Environmental factors associated with abuse are high-crime neighborhoods, poverty, and unemployment (U.S. Department of Health and Human Services, Administration on Children, Youth and Families, 2009). In summary, child maltreatment is multiplydetermined with many convergent pathways (Belsky, 1993).

Parent-child interactions in maltreating families are characterized as more aversive (Belsky, 1993; Cerezo, 1997; Milner \& Chilamkurti, 1991), and poor parenting and disciplinary skills are associated with abuse (Cerezo, 1997). Attention on the parentchild interactions has increased as a means to identify maltreating families and as a point 
of intervention. Indeed, parent training programs have shown efficacy in preventing and remediating child maltreatment (e.g., Chadwick Center for Children and Families, 2004; Chaffin, Silvosky, Funderburk, Valle, Brestan, Balachova, Jackson, Lensgraf, \& Bonner, 2004; Lundahl, Nimer, \& Parsons, 2006). Accurate ways to assess for child physical abuse are needed, and direct observations may provide a method to determine family interactions that engender abuse in order to identify families for intervention.

\section{Observational Studies of Parent-Child Interactions with Child Abuse Samples}

The literature on observations of parent-child interactions is contradictory with respect to differences between families with and without a known history of maltreatment. In general, literature shows that parents who maltreat their children are more aversive, less positive, and less involved when interacting with their children (Wilson, Rack, Shi, \& Norris, 2008). However, comparison among observational studies of parent-child interaction is difficult because these studies utilize a variety of coding systems and operational definitions of behaviors. Additionally, some studies group specific behaviors into larger categories encompassing similar behaviors and do not analyze the specific behaviors themselves. The following sections describe the findings with regard to the specific behaviors included in this study: praise, commands, and negative talk.

\section{Praise}

The literature is split on whether maltreating parents use less positive talk/praise or if no difference exists between the groups. Both Burgess and Conger (1978) and Bousha and Twentyman (1984) found that maltreating parents less frequently displayed positive talk or verbal affection. Burgess and Conger (1978) observed approximately 4 
hours of family interaction in the home using the Behavioral Observation Scoring System during three tasks: construction, skill, and discussion. The sample was drawn from a rural area and included an abuse group ( $\mathrm{n}=17)$, neglect group ( $\mathrm{n}=17)$, and group of families (n=19) with no known history of abuse or neglect but who had similar family size, age of parents and children, income, and education level. Burgess and Conger (1978) found that the mothers in the abuse sample engaged in less positive talk than the control mothers, while the fathers in the abuse sample did not differ in this regard. However, Burgess and Conger (1978) did not note which parent in the sample was responsible for the abuse or whether both parents were responsible.

Bousha and Twentyman (1984) conducted their study in an urban area and examined mother-child interactions in an abusive $(n=12)$, neglectful $(n=12)$, and control sample ( $\mathrm{n}=12)$ matched for age, race, class, and family size. Mother-child dyads were observed in the home for 90 minutes on three consecutive days during which time they were told to act as they would normally. Interactions were coded using codes from Interactional Language (Baldwin \& Ward, 1973). The abusive mothers displayed less verbal affection than the control mothers.

Borrego, Timmer, Urquiza, and Follette (2004) examined praise using the Dyadic Parent-Child Interaction Coding System-II (Eyberg, Bessmer, Newcomb, Edwards, \& Robinson, 1994). 30 mother-child dyads (15 abuse, 15 nonabuse) were videotaped during three 5-minute situations that required increasing levels of parental control. In the first, the parent was instructed to let the child lead the play. In the second, the parent was instructed to lead the play. In the third situation, the parent was instructed to direct the child to put away the toys without the parent's assistance. Borrego and colleagues (2004) 
found that abusive parents used significantly fewer praise statements than nonabusive parents. The samples were similar in mother age and child gender. The groups differed slightly on the demographic variables of ethnicity, mother's marital status, mother's highest education level, socioeconomic status, and child age. Specifically, the abuse group had more African Americans, more single mothers, lower education achievement, lower socioeconomic status, and slightly older children than the nonabuse group.

Wilson, Morgan, Hayes, Bylund, and Herman (2004) examined praise; however praise was combined into the category "soliciting/ affirming," which also included questions about the child's perceptions and feelings. In this study, 42 mothers were recruited from two community agencies where they received services. The mothers were observed in the clinic during a 12 minute play task and clean up, and they completed the Child Abuse Potential Inventory. Higher child abuse potential was significantly correlated with fewer observed "soliciting/ affirming" behaviors.

In contrast, a few studies found no significant difference in praise or positive talk. Lahey, Conger, Atkeson, and Treiber (1984) observed 24 mother-child dyads, 8 in each group, in the home using the Behavioral Observation Scoring System that was used by Burgess and Conger (1978). Abusive mothers were compared to two control groups. In one control group, mother-child dyads matched the abusive group in socioeconomic status, marital status, family size, income, education level, ethnicity, and age of mother and child. In the other control group, mother-child dyads were matched on all demographic characteristics except socioeconomic status. Lahey and colleagues (1984) found no significant results but a trend toward abusive mothers having a lower percentage of positive behaviors, which included verbal positives. Having 8 mother-child 
dyads in each group may not have provided sufficient power to detect significant differences.

Mash, Johnston, and Kovitz (1983) observed 18 mother-child dyads with a history of abuse and 18 mother-child dyads with no known history of abuse. The control group was matched for age, sex, and intelligence of child but had a significantly higher socioeconomic status than the abusive group. The mother-child dyads were videotaped in the clinic during two 15-20 minute situations: free play and a more stressful task such as clean up. The videotapes were coded using the Response-Class Matrix (Mash, Terdal, \& Anderson, 1973) which included a code for praise. No difference was found in the use of praise between the two groups.

Bennett, Sullivan, and Lewis (2006) tested the utility of observations in identification of maltreating families. 139 mother-child dyads were videotaped in the clinic during a teaching task. The length of observation was not specified. 58 of the mothers had substantiated incidents of maltreatment that included abuse $(n=27)$, neglect $(n=19)$, and combined abuse and neglect $(n=12)$. These 58 mothers with known history of maltreatment were combined for analyses. Coders blind to CPS status viewed the videotapes and rated chosen behaviors on a 5-point scale, in which 1 indicated "never observed” and 5 indicated "almost always observed.” The categories of "mother accurately describes behavior in global manner when child succeeds" and "mother expresses pride when child is successful” could be considered praise (p. 66). Bennett and colleagues (2006) found no difference in the ratings of these behaviors in the maltreatment group compared to the control group. However, this study had many limitations. The control mothers in this study were significantly older, had higher 
education, and had more professional jobs (e.g., professional, or owner of major business as opposed to unemployed) than the mothers in the maltreatment group. Additionally, the combination of different types of maltreatment into one group may have obscured meaningful differences in the observation as differences are more likely to be found when abuse and neglectful parents are examined separately (Wilson, et al., 2008). Finally, the global Likert-like scale used to rate behaviors may not have been sensitive enough to differentiate the praise-like behaviors between the maltreating and nonmaltreating mothers.

While the results on differences in the use of praise are contradictory, the majority of the studies found significant differences or non-significant trends indicating that abusive caregivers used praise less frequently than control caregivers.

\section{Commands}

Among the studies that examined commands, instructions, or "directives," there were contradictory results on whether abusive parents differed from nonabusive parents. During observation in the clinic, Mash and colleagues (1983) found that abusive mothers were more directive but only during a structured task situation that required the mother to guide the child through activities such as clean up and completing mazes. The abusive mothers were no more directive than the nonabusive mothers during the unstructured play situation. This implies that the abusive mothers became more directive in response to having to exert more control on their child's behavior.

Another study in the clinic (Oldershaw, Walters, \& Hall, 1986) found that abusive mothers gave more commands than control mothers during non-structured play and structured tasks such as clean up. Oldershaw and colleagues (1986) videotaped 10 abuse 
and 10 matched control mother-child dyads in the clinic for 40 minutes. Control mothers were matched for income, education level, marital status, and age of child. However, control mothers were slightly older than the abusive mothers. The videotapes were coded for maternal use of control strategies, commands, child compliance, and repetition of a maternal verbal behavior. Oldershaw and colleagues (1986) attributed the higher occurrence of commands to the repetitive chain of commands resulting from the child noncompliance, as the children in the abuse group were found to be more noncompliant in the observation.

Cerezo, D’Ocon, and Dolz (1996) also found that abusive mothers gave more instructions. 47 mother-child dyads from an urban area were observed in the home for 3 to 8 one-hour sessions with no assigned task. 23 of the mother-child dyads had a history of abuse and 24 mother-child dyads had no known history of abuse. The groups differed in that the abusive mothers reported more child behavior problems, less social support, and more depressive symptoms. Cerezo and colleagues (1996) used the Standardized Observation Codes III (Cerezo, 1991; Cerezo, Keesler, Dunn, \& Wahler, 1986). Cerezo and colleagues (1996) found that a maternal instruction was the predictor that accounted for the most variance in prediction of abuse status. However, it is unclear if this an artifact of more reported noncompliance in children of abusive mothers.

In contrast, a number of studies found that abusive parents gave fewer commands than non-abusive parents. Bousha and Twentyman (1984) found that maltreating mothers gave less "verbal instruction" than control mothers in their in-home study with no given task. This study assessed differences in mother-child interactions in an urban sample during in-home observations that occurred over three days and consisted of a total of 270 
minutes of observation. The mothers were told to act "normally" and were not given any specific tasks.

Kavanagh, Youngblade, Reid, and Fagot (1988) combined instructions into “positive parenting” behaviors that included "cooperative play" and to "comment favorably.” Kavanagh and colleagues (1988) videotaped 45 parent-child dyads for approximately 12 minutes during free play and clean up using the Interactive Behavior Code (Fagot, 1984). Control families ( $n=23)$ were matched to abuse families $(n=22)$ in marital status, family size, child age, and socioeconomic status. Kavanagh and colleagues (1988) found that $49.8 \%$ of abusive parents engaged in positive parenting strategies as opposed to $64.9 \%$ of nonabusive parents, which may imply that abusive parents gave fewer instructions. No analyses were presented to indicate whether there was a difference in positive parenting behavior between free play and clean up.

Dolz, Cerezo, and Milner (1997) divided instructions into positive, negative, or neutral, and the authors then combined these behaviors into the categories of "mother positive behavior," “mother negative behaviors,” or "mother neutral instruction.” In this study, 28 mother-child dyads were observed in the home for 5 one-hour sessions over two weeks using the Standardized Observation Codes III. The abusive mothers showed a trend toward more neutral instructions. It is possible that there were no differences in positive instructions as no difference was found in "mother positive behaviors," and a higher number of negative instructions could be inferred from the higher instance of "mother negative behaviors." However, other behaviors grouped into the positive and negative categories also could have accounted for the differences. 
In contrast, Wilson and colleagues (2004) found no significant relation between child abuse potential and "directives" during a brief unstructured play task at a community mental health agency. The study observed 42 mothers in the clinic during free play and clean up. Relations between parent verbal behaviors and parent scores on the Child Abuse Potential Inventory (Milner, 1986) were examined in this study.

While the literature is contradictory, commands seem most likely to differentiate abusive parents from non-abusive parents during structured tasks in which abusive caregivers must exert more control over their child's actions and when children are more noncompliant. Observed child behavior and parent-reported behavior often differed between the abuse and control groups, making it unclear if the differences in command use were reactions to child behavior or characteristic of a more controlling parental style.

\section{Negative Talk}

Negative talk, also labeled criticism, has contradictory research findings as well. Studies conducted in the clinic found that criticism did not distinguish between the two groups (Bennett, et al., 2006; Kavanagh, et al; 1988; Wilson, et al., 2004). Additionally, Bousha and Twentyman's (1984) study conducted in the home found no difference in mother's negative verbal behavior. The preponderance of investigations would suggest that maltreating parents do not use negative talk or criticism more frequently than control parents.

However, the difference between frequency and ratio may need to be considered when interpreting these findings as abusive caregivers tend to display less overall talk than control parents (e.g., Burgess, \& Conger, 1978; Bousha \& Twentyman, 1984; Lahey, et al., 1984). For example, when examining the total frequency of negative talk, 
Lahey and colleagues (1984) did not find a difference during in-home observations. Yet, when the number of negative verbalizations was compared to the overall number of verbalizations, the authors found that abusive parents provided a significantly greater percentage of negative verbalizations than non-abusive parents. The results of the inhome study of Burgess and Conger (1978) support this finding and highlight the importance of considering not just the amount of negative talk but the ratio of negative verbalizations to the overall number of verbalizations.

\section{Amount of Interaction}

Of the studies that compared the total amount of interaction, all found that maltreating parent-child dyads had lower overall rates of interaction than nonmaltreating parent-child dyads (Burgess \& Conger, 1978; Bousha \& Twentyman, 1984; Lahey, et al., 1984). In Bousha and Twentyman’s (1984) study, social interaction was a separate category defined as "subject engages with another person in the behavioral categories listed above with the following exceptions and additions” to not include solitary play, noncompliance, and initiation, and to include any interactions that did not fit in a listed behavioral category (e.g., passing food at the dinner table; p. 109). Burgess and Conger (1978) and Lahey and colleagues (1984) measured interactions as the total number of codes.

\section{Summary of Current Literature}

The literature of observational studies comparing parents with a history of abuse to those with no known history of abuse is mixed, and methodological differences may account for some of these contradictory findings. First, the coding systems used are diverse with few studies using the same approach. Many of these coding systems, with 
the exception of the DPICS-II use by Borrego and colleagues (2004), were developed for the purpose of research (e.g., Bennett, et al., 2006; Bousha \& Conger, 1984; Burgess \& Conger, 1978; Cerezo, et al., 1996; Kavanagh, et al., 1988; Lahey, et al., 1984; Lorber, et al., 1984; Mash, et al., 1983) and have not achieved widespread use in clinical applications. Variations in definitions of behavioral categories also may have contributed to the differences in results found in the literature.

Second, studies vary in the strength of the comparison group. Most of the studies attempted to match the control with the abuse sample in terms of age, family size, income, and education level. However, some investigations still reported marked differences in socioeconomic status between groups (e.g., Mash, et al, 1983). Some studies observed compliance of children (e.g., Oldershaw, et al., 1986), and others compared maternal report of child behavior problems (e.g., Cerezo, et al., 1996). However, while these differences were noted, no studies statistically controlled for differences in child behavior when examining parental behavior. It is possible that group differences in parental behavior may have resulted in part from parental response to child misbehavior during the observation. Thus, these differences in the strength of the comparison group in terms of controlling for extraneous caregiver, family, and child characteristics may account for some of the contradictory findings in the literature.

The situations in which families were observed differ markedly across studies. Parent-child dyads were observed in the home with no given task (e.g., Bousha \& Twentyman, 1984) and with structured tasks only (e.g., Burgess \& Conger, 1978). Other studies observed parent-child dyads in the clinic with structured tasks only (e.g., Bennett, et al., 2006) or with both structured and unstructured tasks (e.g., Kavanagh, et al., 1988). 
Additionally, some observations were coded live (e.g., Burgess \& Conger, 1978) while others were coded from videotape (e.g., Oldershaw, et al., 1986). Finally, observations varied in length from a one-time 12 minute session (Wilson, et al., 2004) to numerous lengthy sessions over different days which totaled in as many as 8 hours of observation (Cerezo, et al., 1996). While longer observations were more likely to yield results (Wilson, et al., 2008), they may be impractical for widespread use in identification of abusive caregivers. These methodological differences in observation location, situation, live or videotaped coding, type of coding system, and length of observation may have contributed to the mixed results regarding observed caregiver behaviors in differences between families with and without a known history of abuse.

\section{Dyadic Parent-Child Interaction Coding System and Parent-Child Interaction}

\section{Therapy}

The Dyadic Parent-Child Interaction Coding System (DPICS; Eyberg, et al., 1994; Eyberg, Nelson, Duke, \& Boggs, 2005) is a standardized and reliable measure of parent-child interactions based on skills targeted in Parent-Child Interaction Therapy (PCIT; Robinson \& Eyberg, 1981). PCIT is an empirically-supported treatment for childhood behavior problems and hyperactivity (Brestan \& Eyberg, 1998; Eisenstadt, Eyberg, McNeil, Newcomb, \& Funderburk, 1993; Eyberg, 1988; Hood \& Eyberg, 2003; Nixon, 2001; Schuhmann, Foote, Eyberg, Boggs, \& Algina, 1998), and has increasing support as an evidenced-based intervention for parents with reports of child physical abuse (Borrego, Urquiza, Rasmussen, \& Zebell, 1999; Chadwick Center for Best Practices, 2004; Chaffin, et al., 2004; Timmer, Urquiza, Zebell, \& McGrath, 2005, Urquiza \& McNeil, 1996). 
PCIT focuses on restructuring the patterns of parent-child interaction by teaching positive parenting skills and discipline skills (Eyberg, 1988). The DPICS is designed to measure the parenting skills taught in PCIT during three five-minute play periods varying in the degree of control exerted by the parent. This allows clinicians to observe parent progress in acquisition of skills, identify strengths and weaknesses, and tailor the treatment to each parent. The use of the DPICS allows one to measure positive parenting skills as defined by an established, evidence-based parent training program with relevance to parents with reports of child physical abuse specifically.

The DPICS can discriminate families with and without children with Oppositional Defiant Disorder (Eyberg, et al., 2005) and is sensitive to treatment effects in parent training programs (Eyberg \& Matarazzo, 1980; Eyberg \& Robinson, 1982; WebsterStratton \& Hammond, 1990).The DPICS has convergent validity with the Parenting Stress Index (Abidin, 1995) and the Eyberg Child Behavior Inventory Intensity Score (Eyberg, et al., 2005; Webster-Stratton, 1985). It has established one-week test re-test reliability (Eyberg, et al., 2005), and inter rater reliability across coding categories ranges from .46 to .90 (see the Appendix).

As PCIT continues to gain support as an evidence-based treatment for caregivers with reports of abuse, the DPICS is increasingly being used to assess treatment effects with child physical abuse samples. Chaffin and colleagues (2004) conducted a randomized control trial to examine the effect of PCIT on recidivism rates (e.g., additional reports of physical abuse) in a sample of parents who had a history of reports of child physical abuse. Results revealed that $19 \%$ of parents who completed PCIT had a re-report of abuse while $49 \%$ of parents who received standard community services had a 
re-report of abuse at median follow-up of 850 days post-treatment. Additionally, the DPICS indicated increases in positive parenting behaviors and decreases in negative parenting behaviors for parents who participated in PCIT. In a study examining the change trajectories during PCIT with parents who have been physically abusive, Hakman and colleagues (2009) found that the DPICS detected changes in observed parent responses to child behavior during the course of therapy and that parent negative behaviors decreased over the course of PCIT. Borrego and colleagues (2004) used the DPICS to examine differences between 15 abusive and 15 nonabusive mothers. However, the results of this study are limited by demographic differences between the groups, such as lower socioeconomic status, lower education levels, and more single mothers, that were not controlled during direct comparison of the groups because the focus of the study was sequential responses of parent behavior to child behavior.

\section{Chapter 2: Current Study}

The purpose of this study was to examine parenting differences in abusive and nonabusive caregivers by using a well-established observational coding system used in clinical settings with physically abusive caregivers while controlling for extraneous demographic variables and child behavior. As the DPICS is a well-established coding system with reliability and validity with child conduct problems and has increasing use in the area of child abuse and neglect, it is potentially a valuable tool to identify differences in parenting behaviors between caregivers with and without reports of child physical abuse. Finally, abusive parent-child dyads were compared to a high-risk sample recruited from Head Start that were similar to abuse populations in socio-economic factors and child behavior problems. Head Start families were chosen for the comparison group 
because they tend to have a lower socioeconomic status, lower education, and higher levels of child behavior problems than a community comparison group. Based on previous investigations of parent-child interactions in this population, total amount of interaction, praise, commands, and negative talk were the focus of this study.

\section{Hypotheses}

\section{Hypothesis One}

Abusive caregivers would have fewer interactions than comparison caregivers as defined by the total number of codes (Burgess \& Conger, 1978; Bousha \& Twentyman, 1984; Lahey, et al., 1984).

\section{Hypothesis Two}

Abusive caregivers would have fewer praise statements than comparison caregivers (Burgess \& Conger, 1978; Bousha \& Twentyman, 1984; Borrego, et al., 2004; Wilson, et al., 2004).

\section{Hypothesis Three}

Abusive caregivers would have more negative talk than comparison caregivers (Burgess \& Conger, 1978; Lahey, et al., 1984).

\section{Hypothesis Four}

Abusive caregivers would give more commands than comparison caregivers (Cerezo, et al., 1996; Mash, et al., 1983; Oldershaw, et al., 1986).

\section{Chapter 3: Method}

\section{Participants}

\section{Abuse Group}


The abuse group consisted of 39 caregiver-child dyads from a sample of 110 dyads collected by Chaffin and colleagues (2004). These dyads participated in a randomized control trial examining the efficacy of Parent-Child Interaction Therapy in reducing recidivism in caregivers with prior reports of physical abuse. The 110 caregiver-child dyads who participated in this study were recruited from central Oklahoma when they entered the welfare system following a new report of child physical abuse. This research was funded by the U.S. Department of Health and Human Services. This data was made available for secondary analyses through the National Archive on Child Abuse and Neglect via Cornell University.

Dyads were included in the study if (a) the caregiver was able to participate with the child and legal termination of parental rights had not begun, (b) the caregiver had a minimum IQ score of 70; (c) the child was between the ages of four and twelve years old, (d) the caregiver did not have a report of sexual abuse, and (e) the parent voluntarily consented to participate in the study. Of 300 caregivers who were referred for the study, 112 dyads met the inclusion criteria for the study. Data from two caregivers initially included in the study were removed because the caregivers did not appear to understand the assessment questions and the data they provided had questionable validity. As the current study focused on caregiver interactions with young children, caregiver-child dyads only were included if the child was between the ages of four- and seven-years-old, yielding 39 caregiver-child dyads in the abuse group.

Caregivers were randomized into three groups that consisted of Parent-Child Interaction Therapy, Parent-Child Interaction Therapy plus motivational enhancement, and standard community treatment. The parenting interventions were completed in 
approximately 6 months at which point the caregivers were re-assessed. Prior to randomization into groups, participants completed a baseline assessment which included interacting in the three structured situations of Child-Led Play, Parent-Led Play, and Clean Up. These interactions were coded using the second edition of the DPICS (DPICS-II; Eyberg, et al., 1994) by research assistants who were naïve to the condition to which the participants were assigned. The DPICS-II data of the Parent-Led Play situation at baseline were used in the current study. For Parent-Led Play, caregivers were instructed to choose any activity and have the child follow their lead.

Prior to coding the interactions for the study, the coders were trained in the coding system and had to demonstrate coding at criterion with standard videotaped stimuli and ongoing coding was periodically assessed for drift. Seven of the videotapes were sent to an independent coder who was not trained, supervised by, or involved with the study. Reliability between the coding of the independent coder and the staff of the study was .94 Kappa for a composite of negative caregiver behaviors and .84 Kappa for a composite of positive caregiver behaviors.

\section{Comparison Group}

The comparison group consisted of 31 caregiver-child dyads collected by Tempel and colleagues (in press). These dyads participated in a previous study examining parental attention and child on-task behavior. Dyads were recruited from Head Start programs in north central West Virginia. Head Start is a national program for lowincome families that provides health, nutrition, education, and parent-involvement services in order to improve children’s academic achievement. 
Caregiver-child dyads were included in the study if (a) the child was currently enrolled in a Head Start program, (b) the child was between the ages of three and five years old, (c) the caregiver responded to research recruitment flyers seeking "active” children, and (d) the caregiver reported that the child did not have a prior diagnosis of a pervasive developmental disability or mental retardation. None of the caregivers recruited from Head Start had known involvement with Child Protective Services.

Participants interacted during an initial 5-minute "warm-up” condition in which the caregivers were instructed to play as they would "typically" and to tell the children, "Now, we are going to practice coloring. You will work on this coloring sheet or on this blank piece of paper. You can draw or color anything that you want.” The coloring task occurred in the family's home or in the local Head Start facility. Dyads were given a paper which contained shapes marked with predetermined colors, and each dyad was given four crayons (e.g., red, yellow, green, and blue) to use in coloring the paper. If the child left the designated area prior to the completion of 5 minutes, the parent prompted the child, "Remember, you need to color."

This interaction was videotaped and coded using the third edition of the DPICS (DPICS-III, Eyberg, et al., 2005). Videotapes were coded by undergraduate research assistants who were trained using videotapes and The Abridged Workbook: Coder Training Manual for the Dyadic Parent-Child Interaction Coding System ( $3^{r d}$ Ed.) (Fernandez, Chase, Ingalls, \& Eyberg, 2006). Prior to coding, coders had to reach minimum reliability of $80 \%$ agreement with pre-coded training tapes and $25 \%$ of the tapes were double-coded to assess inter rater reliability and prevent coder drift. Inter 
rater reliability was below .60 Kappa on four videotapes, and coders were re-trained and the data was re-coded.

\section{Measures}

\section{Demographic Information}

Caregivers in both groups completed demographic questionnaires that included caregiver age, child age, caregiver gender, child gender, relationship to the child (e.g., biological parent, adoptive parent, aunt), race, annual household income, highest level of education attained, marital status, and employment status.

\section{Dyadic Parent-Child Interaction Coding System}

The Dyadic Parent-Child Interaction Coding System (DPICS; Eyberg, et al., 1994; Eyberg, et al., 2005) is an observational coding system designed to assess a number of parent and child behaviors. Reliability and validity have been shown in both live and videotaped observations for the DPICS (Robinson \& Eyberg, 1981; Eyberg, et al., 2005). Convergent validity has been established with the Parenting Stress Index (PSI; Abidin, 1995) Child Domain Scores, PSI Parent Domain Scores, PSI Parent Locus of Control Scores, and the Eyberg Child Behavior Inventory Intensity Score (Eyberg, et al., 2005; Webster-Stratton, 1985). Discriminative validity of the behavioral categories has been shown between normal families and those families with a child identified with Oppositional-Defiant Disorder (ODD; Eyberg, et al., 2005).

Treatment sensitivity has also been demonstrated in that caregivers had more positive behaviors and fewer negative behaviors following treatment for children with ODD (Eyberg \& Matarazzo, 1980; Eyberg \& Robinson, 1982; Schuhmann, Foote, Eyberg, Boggs, \& Algina, 1998; Webster-Stratton \& Hammond, 1990). Test- retest 
reliability for a one-week period has been established for parent critical statements and parental praise at pretreatment during parent led play and clean up (Eyberg, et al., 2005). Pearson's correlations for parent critical statements were .34 for parent led play and .39 for clean up, $p<.001$, (Eyberg, et al., 2005, p.222). Pearson's correlations for parent praise were .47 for parent led play and .57 for clean up, $p<.001$, (Eyberg, et al., 2005, p.222). Interrater reliability with Cohen’s kappa ranges from .46 to .90 for the behavioral categories of the DPICS. Cohen’s kappa ranges from .49 to .68 for labeled praise, .66 to .70 for unlabeled praise, .57 to .62 for critical statements/ negative talk, .65 to .69 for direct commands, .64 to .63 for indirect commands, and .69 to .71 for child compliance. Operational definitions of the categories of labeled and unlabeled praise, direct and indirect commands, critical statements/ negative talk, and child noncompliance are the same for both the DPICS-II and the DPICS-III. The category of Critical Statement in the DPICS-II was renamed as Negative Talk in the DPICS-III. Other categories were renamed (i.e., Information Description became Neutral Talk) or multiple categories were collapsed into one category (i.e., many categories of child talk became Child Prosocial Talk). The changes between the second and third edition of the DPICS did not affect the variables examined in the current study.

For the current study the parent behaviors of praise (labeled and unlabeled combined), commands (direct and indirect combined), negative talk/ critical statements, child noncompliance, and total combined parent codes across all parent verbal categories were examined. Noncompliance rate was defined as total instances of noncompliance divided by total commands. Noncompliance occurred when the child did not completely perform, begin to perform, or attempt to perform a parental request within 5 seconds; 
thus, it is the opposite of child compliance. The parent-led play condition from the abuse data were compared to the observations in the comparison data. The coloring task is most similar to the parent-led play condition because the children are not able to choose the "game" in either of these conditions and parents must exert some control to keep the child engaged with the chosen activity. Inter rater reliability for each subscale as well as specific definitions and examples for each category can be found in the Appendix.

\section{Chapter 4: Results}

The data from 70 caregiver-child dyads were included in analyses. Descriptive statistics were examined for all variables. Independent samples $t$-tests were conducted to examine potential group differences in the demographic variables of child age, parent age, child noncompliance rate, and total talk. Chi-square tests were conducted to examine potential group differences in the categorical demographic variables of child gender, caregiver gender, race, relation of caregiver to child, marital status, and caregiver's highest level of education. Variables that had significant differences between the groups were further examined to understand their relations to the variables of total praise, total commands, and negative talk/ critical statements. Analyses of covariance were conducted to examine group differences in total praise, total commands, and negative talk/ critical statements when controlling for extraneous demographic differences and total talk. Hierarchical logistic regression was conducted to understand the ability of total praise, total commands, and negative talk/ critical statements to predict abuse group status. Lastly, these same analyses were performed using a subsample of 41 dyads from the total sample that included only children aged four- and five-years-old.

\section{Results with the Full Sample of 70 Caregiver-Child Dyads}




\section{Demographics.}

Data from 70 children of ages three- to seven-years-old $(M=4.97, S D=1.18$;

$60 \%$ male) and their caregivers who ranged in age from 19 - to 60 -years-old ( $M=30.13$, $S D=7.75 ; 84 \%$ female) were utilized for these analyses. The majority of caregivers (77\%) were biological mothers, with the remaining being comprised of biological fathers (10\%), stepmothers (3\%), stepfathers (1\%), grandmothers $(1 \%)$, and great grandmothers (7\%). The majority of caregivers (71\%) were Non-Hispanic, Caucasian, followed by Black/ African American (19\%), Hispanic/ Latino (3\%), and Other (i.e., Asian, American Indian; 6\%). The majority of caregivers were married or living with a significant other (54\%), followed by never married (24\%), and divorced or separated (19\%). As for the caregiver's highest level of education obtained, 7\% had ninth-grade or less, 20\% had completed less than a twelfth-grade education, $43 \%$ had earned a high school diploma or equivalent, $10 \%$ had gone to vocational school, $14 \%$ had some college, $4 \%$ had earned a four-year college degree, and $1 \%$ had gone to graduate school. Children’s noncompliance rate (noncompliance/ total parental commands) during the observation was .13 $(S D=.28)$.

\section{Examination of potential differences between groups on demographic}

\section{variables and child behavior.}

See Table 1 for demographic characteristics by group.

The results of independent samples $t$-tests revealed that the groups did not differ with regard to parent age, $t(68)=.99, p=N S$, or child noncompliance rate, $t(67)=1.37, p$ $=$ NS. Contingency table analyses indicated that there were not significant differences between the groups with regard to child gender, $X^{2}(1, \mathrm{~N}=70)=.84, p=N S$, caregiver 
gender, $X^{2}(1, \mathrm{~N}=70)=.05, p=N S$, relation of caregiver to child, $X^{2}(5, \mathrm{~N}=70)=.28, p$ $=N S$, caregiver's highest education level, $X^{2}(6, \mathrm{~N}=70)=.08, p=N S$, or caregiver marital status, $X^{2}(2, \mathrm{~N}=70)=.17, p=N S$.

However, results of an independent samples $t$-test revealed that children in the abuse group $(M=5.64, S D=1.01)$ were significantly older than the children in the comparison group $(M=4.13, S D=.76), t(68)=-6.90, p<.01$. Correlations indicated that older child age was associated with more total talk $(r=.24, p<.05)$ and less total praise ( $r=-.48, p<.01$; see Table 4 ). When examining the relations between child age and praise in the abuse sample only, child age was still significantly associated with less total praise, $r=-.32, p<.05$. However, there was not a significant relation of child age with either total commands $(\mathrm{r}=.04, p=N S)$ or negative talk $(\mathrm{r}=-.03, p=N S$; see table 4). When examining child age in the abuse sample only, it was not significantly related to total talk $(\mathrm{r}=-.14, p=N S)$, commands $(\mathrm{r}=-.13, p=N S)$, or negative talk $(\mathrm{r}=-.19, p=$ $N S$ ). Child age was controlled in further analyses because children in the abuse group were significantly older than children in the comparison group.

A 2 X 4 contingency table analysis revealed a significant difference between the groups in the race of the caregiver, $X^{2}(3, \mathrm{~N}=69)=15.73, p<.01$. The abuse group contained 21 (55\%) caregivers who identified as Non-Hispanic, Caucasian, 13 (34\%) as Black/ African American, two (.05\%) as Hispanic/ Latino, and two (.05\%) as "Other” (see Table 1). However, the comparison group contained 29 (94\%) caregivers who identified as Non-Hispanic, Caucasian, none as Black/ African American, none as Hispanic/ Latino, and two (6\%) as “Other” (see Table 1). The race variable was missing 
for one caregiver in the abuse group and therefore that participant's race was not included in these analyses.

Results of one-way analyses of variance indicated that individuals who identified as different races did not differ with regard to child's age, $F(3,65)=1.74, M S E=1.35$, $p$ $=N S$, total praise, $F(3,65)=1.17, M S E=11.75, p=N S$, total commands, $F(3,65)=$ $1.71, M S E=140.27, p=N S$, or negative talk, $F(3,65)=.49, M S E=25.44, p=N S$ (see Table 12). However, a one-way ANOVA with follow-up Bonferroni comparisons revealed that individuals who identified as Black/ African American had more total talk $(M=89.75, S D=30.00)$ than did individuals who identified as Non-Hispanic, Caucasian $(M=61.64, S D=28.67), F(3,64)=3.59, M S E=811.86, p<.05$ (see Table 12$).$ There were not significant differences in total talk between the other groups. Race was dichotomized into Caucasian and Non-Caucasian because this differentiated the groups based on child age, $t(67)=-2.06, p<.05$, and total talk after controlling for child age, $F$ $(1,65)=8.16, p<.01$. Non-Caucasian caregivers had older children $(M=5.42, S D=$ 1.07) than Caucasian caregivers $(M=4.78, S D=1.18)$. After controlling for child age, Non-Caucasian caregivers talked more $(M=86.72, S D=26.67)$ than Caucasian parents $(M=61.64, S D=28.67)$. Dichotomizing race by Black/ African American and NonBlack/ African American did not differentiate groups based on child age, $t(-67)=-.11, p$ $=N S$, or total talk after controlling for child age, $F(2,65)=2.72, M S E=813.34, p=N S$. Race was controlled in analyses examining differences between groups on total talk because total talk differed by race and in the logistic regression because the groups differed by race. Race was not controlled in analyses examining differences between 
groups for praise, commands, or negative talk because these variables did not differ by race.

\section{Comparison of Groups.}

Hypothesis 1: Caregivers in the Abuse group will have a lower total talk than the comparison caregivers as defined by the total codes.

After controlling for child age and caregiver race, an analysis of covariance (ANCOVA) revealed that caregivers in the abuse group had more total talk ( $M=84.57$, $S D=26.32)$ than the comparison group $(M=48.84, S D=21.78), F(1,64)=25.75, M S E$ $=566.53, p<.01$ (see table 2). More total talk was associated with more total commands $(\mathrm{r}=.67, p<.01)$ and more negative talk $(\mathrm{r}=.50, p<.01$; see Table 4). Total talk was not associated with total praise $(\mathrm{r}=.12, p=N S$; see Table 4$)$. Total talk was controlled in further analyses because it differed by group.

\section{Hypothesis 2: Caregivers in the abuse group will have fewer praise statements} than the comparison caregivers.

Controlling for child age and total talk, an ANCOVA revealed that individuals in the abuse group provided significantly less praise $(M=1.29, S D=2.51)$ than did individuals in the comparison group $(M=4.10, S D=3.82), F(1,65)=13.66, M S E=$ $7.35, p<.01$ (see table 2).

Hypothesis 3: Caregivers in the abuse group will have more negative talk than the comparison caregivers.

When controlling for child age and total talk, an ANCOVA revealed no significant difference in amount of negative talk/ critical statements between caregivers 
in the abuse group $(M=4.87, S D=3.90)$ and comparison group, $(M=2.87, S D=5.93)$, $F(1,65)=.07, M S E=18.65, p=N S$ (see table 2 ).

Hypothesis 4: Caregivers in the abuse group will have more commands than the comparison caregivers.

When controlling for child age and total talk, an ANCOVA revealed no significant difference in number of commands between caregivers in the abuse group ( $M$ $=18.74, S D=13.40)$ and the comparison group, $(M=10.42, S D=8.66), F(1,65)=.001$, MSE $=83.45, p=N S$ (see table 2).

\section{Logistic Regression.}

Refer to table 3 for descriptive statistics and table 4 for correlations among the variables. A hierarchical logistic regression analysis was conducted predicting membership in the abuse group (refer to Table 5). Child age, race, and total talk were entered into the first step. Total praise, total commands, and negative talk were entered into the second step. Over and above child age, race, and total talk, only total praise significantly predicted abuse group status, Wald Test $=4.18, p<.05(\operatorname{Exp}(\mathrm{B})=.32,95 \%$ CI: .11 - .95). Increase in one praise statement decreased the likelihood of being in the abuse group by 68\%. Total commands and negative talk did not predict abuse group status.

\section{Results with Four- and Five-Year-Old Children Only}

\section{Demographics.}

Data from 41 children of ages four- to five-years-old $(M=4.54, S D=.50 ; 59 \%$ male) and their caregivers who ranged in age from 19 - to 60 -years-old $(M=31.44, S D=$ 8.67; 78\% female) were utilized for these analyses. The majority of caregivers (78\%) 
were biological mothers, with the remaining being comprised of biological fathers (12\%), stepfathers (2\%), grandmothers (2\%), and great grandmothers (5\%). The majority of caregivers (78\%) were Non-Hispanic, Caucasian, followed by Black/ African American (15\%), and Other (i.e., Asian, American Indian; 7\%). The majority of caregivers were married or living with a significant other (63\%); with equal numbers being never married (17\%) and divorced or separated (17\%). As for the caregiver's highest level of education obtained, $5 \%$ had ninth-grade or less, $17 \%$ had less than a twelfth-grade education, $46 \%$ had earned a high school diploma or equivalent, 7\% had gone to vocational school, 15\% had some college, $7 \%$ had earned a four-year college degree, and $2 \%$ had gone to graduate school. Children’s noncompliance rate (noncompliance/ total commands) during the observation was $.14(S D=.25)$.

\section{Examination of potential differences between groups on demographic}

\section{variables and child behavior.}

See Table 6 for demographic characteristics by group. The results of independent samples $t$-tests revealed that the groups did not differ with regard to parent age, $t(39)=$ $.89, p=N S$, child age, $t(39)=-1.19, p=N S$, or child noncompliance rate, $t(38)=.68, p=$ NS. The mean difference for parent age was 2.46 years, the mean difference for child age was .19 years, and the mean difference for child noncompliance rate was .05.

Contingency table analyses indicated that there were not significant differences between the groups with regard to child gender, $X^{2}(1, \mathrm{~N}=41)=1.58, p=N S$, relation of caregiver to child, $X^{2}(4, \mathrm{~N}=41)=4.25, p=N S$, caregiver's highest education level, $X^{2}$ $(6, \mathrm{~N}=41)=8.67, p=N S$, or caregiver marital status, $X^{2}(2, \mathrm{~N}=41)=1.20, p=N S$. 
However, A 2 X 3 contingency table analysis revealed a significant difference between the groups in the race of the caregiver, $X^{2}(2, \mathrm{~N}=41)=9.93, p<.01$. The abuse group contained 10 (59\%) caregivers who identified as Non-Hispanic, Caucasian, 6 (35\%) as Black/ African American, and one (.06\%) as “Other.” However, the comparison group contained 22 (92\%) caregivers who identified as Non-Hispanic, Caucasian, none as Black/ African American, and two (8\%) as “Other.” Results of oneway analyses of variance indicated that individuals who identified as different races did not differ with regard to any of the variables of interest; total talk, $F(2,38)=1.88, M S E=$ 983.43, $p=N S$, total praise, $F(2,38)=.96, M S E=11.13, p=N S$, total commands, $F(2$, $38)=1.00, M S E=129.79, p=N S$, or negative talk, $F(2,38)=.69, M S E=19.66, p=N S$. For total talk, the mean difference was 24.16 between Caucasian and African American, 20.16 between Caucasian and Other, and 4 between African American and Other. For total praise, the mean difference was 1.41 between Caucasian and African American, 2.24 between Caucasian and Other, and .83 between African American and Other. For total commands, the mean difference was 4.86 between Caucasian and African American, 7.86 between Caucasian and Other, and 3 between African American and Other. For negative talk, the mean difference was .99 between Caucasian and African American, 2.68 between Caucasian and Other, and 3.67 between African American and Other. The mean differences are noted because the sample size may not provide sufficient power to detect differences. Analyses examining total talk and the logistic regression were run both including and excluding race because differences, though not statistically significant, were large for total talk and the sample size may not have provided sufficient power to detect a difference. 
Additionally, a 2 X 2 contingency table analysis revealed a significant difference between the groups in the caregiver gender, $X^{2}(1, N=41)=5.10, p<.05$. Ten of seventeen (63\%) caregivers in the abuse group were female while 22 of 24 (92\%) caregivers in the comparison group were female. Independent samples t-tests revealed no significant differences between caregiver gender for praise, $t(38)=1.38, p=N S$, or negative talk, $t(38)=.33, p=N S$. However, independent samples $t$-tests revealed that males talked significantly more $(M=83.75, S D=33.89)$ than females $(M=54.03, S D=$ 29.08), $t(38)=2.51, p<.05$, and males gave significantly more commands $(M=23.50$, $S D=16.85)$ than females $(M=10.16, S D=10.16), t(38)=3.27, p<.01$. Caregiver gender was controlled in further analyses.

\section{Comparison of Groups.}

\section{Hypothesis 1: Caregivers in the Abuse group will have a lower total talk than}

\section{the comparison caregivers as defined by the total codes.}

After controlling for caregiver gender, an ANCOVA revealed that caregivers in the abuse group talked significantly more $(M=83.88, S D=30.11)$ than caregivers in the comparison group $(M=44.04, S D=21.83), F(1,37)=16.86, M S E=633.01, p<.01$, partial eta squared $=.29$. After controlling for both caregiver gender and dichotomized race (Caucasian and Non-Caucasian), an ANCOVA indicated that caregivers in the abuse group still talked significantly more $(M=83.88, S D=44.04)$ than caregivers in the comparison group $(M=44.04, S D=21.83), F(1,36)=14.40, M S E=650.73, p<.01$ (see table 7). More total talk was associated with more commands $(\mathrm{r}=.65, p<.01)$ and more negative talk $(\mathrm{r}=.60, p<.01$; see Table 9$)$. More total talk was not associated with praise $(\mathrm{r}=.24, p=N S)$. Total talk will be controlled in further analyses because 
caregivers in the abuse group talked significantly more than caregivers in the comparison group.

Hypothesis 2: Caregivers in the abuse group will have fewer praise statements than the comparison caregivers.

After controlling for total talk and caregiver gender, an ANCOVA revealed that caregivers in the abuse group gave significantly less praise $(M=1.88, S D=3.40)$ than caregivers in the comparison group $(M=3.00, S D=3.35), F(1,36)=9.16, M S E=9.06$, $p<.01$, partial eta squared $=.20$ (see table 7$)$.

Hypothesis 3: Caregivers in the abuse group will have more negative talk than the comparison caregivers.

After controlling for caregiver gender and total talk, an ANCOVA revealed no significant differences in amount of negative talk/ critical statements between the groups in frequency of commands, $F(1,36)=.01, M S E=72.07, p=N S$, partial eta squared $=.00$ (see table 7).

Hypothesis 4: Caregivers in the abuse group will have a more commands than the comparison caregivers.

After controlling for caregiver gender and total talk, an ANCOVA revealed no significant differences between caregiver's frequency of negative talk, $F(1,36)=.162$, $M S E=12.78, p=N S$, partial eta squared $=.01$ (see table 7).

\section{Logistic Regression.}

Refer to table 8 for descriptive statistics and table 9 for correlations among the variables. A hierarchical logistic regression analysis with the families with 4-5- year-old children was conducted predicting membership in the abuse group (refer to Table 10). 
Caregiver gender and total talk were entered into the first step. Total praise, total commands, and negative talk were entered into the second step. Over and above caregiver gender and total talk, only total praise significantly predicted abuse group status, Wald Test $=5.60, p<.05(\operatorname{Exp}(B)=.45,95 \%$ CI: .24 - .87). Increase in one praise statement decreased the likelihood of being in the abuse group by 55\%. Total commands and negative talk did not predict abuse group status.

A second hierarchical regression was conducted predicting membership in the abuse group (refer to Table 11). Dichotomized race, caregiver gender, and total talk were entered into the first step. Total praise, total commands, and negative talk were entered into the second step. Over and above caregiver gender, caregiver race, and total talk, only total praise significantly predicted abuse group status, Wald Test $=5.08, p<.05$ (Exp (B) $=.47,95 \%$ CI: .25-.91). Increase in one praise statement decreased the likelihood of being in the abuse group by 53\%. Total commands and negative talk did not predict abuse group status.

\section{Chapter 5: Discussion}

The purpose of this study was to examine caregiver-child interactions between caregivers with and without prior reports of physical abuse. Strengths of this study were that it measured behaviors during the interaction using a well-established coding system that is commonly used with physically-abusive parents referred for treatment and that it examined and statistically controlled for differences in demographic and child behavior variables. The results of this study indicated that the caregiver use of praise was a distinguishing factor between caregivers with and without prior reports of physical abuse, which supported the hypothesis. Additionally, this finding replicated prior research that 
has found physically abusive caregivers to provide less praise, verbal affection, or positive talk than control caregivers (Borrego, et al., 2004; Bousha \& Twentyman, 1984; Burgess \& Conger, 1978; Wilson, et al., 2004). The current study extended these findings by demonstrating that praise remained a significant predictor of abuse status after controlling for child behavior, total talk, child age, child gender, caregiver age, caregiver gender, caregiver education, race, and relation of caregiver to child.

Additionally, the finding that abusive caregivers gave significantly less praise than comparison caregivers was consistent when both a larger sample was used in this study and when the child's age was narrowed to include only 4- and 5-year-olds. Interestingly, while caregivers in the abuse group spoke more than caregivers in the comparison group, which was associated with more commands and more negative talk, more total talk was not associated with more praise.

Additionally, the results of the current study replicated the findings of previous studies that did not find negative talk or criticism to differentiate abusive and comparison caregivers (Bennett, et al., 2006; Kavanagh, et al., 1988; Wilson, et al., 2004). Contrary to the present hypotheses, this finding remained after controlling for the amount of total talk, which failed to replicate previous research that found negative talk to differ when examined in the context of the total interaction of the caregiver and child (Burgess \& Conger, 1978; Lahey, et al., 1984). A difference between the current study and previous research was that abusive parents were more talkative with their children than the comparison caregivers. Thus, while the frequency of negative talk was actually greater with abusive caregivers than comparison caregivers, when controlling for the greater overall amount of talking, the differences were not significant. 
In examination of command frequency, a strength of the current study was that child noncompliance during the observation was measured and found to be equivalent across groups. The observed situation required caregivers to exert a moderate amount of control to keep the child playing with the caregivers' choice of game, which had been associated with more caregiver use of commands in abusive samples. In contrast to the current study, Mash and colleagues (1983), Oldershaw and colleagues (1986), and Cerezo and colleagues (1996) found that abusive caregivers gave more commands during structured tasks. However, results were potentially confounded by differences in caregiver-reported (Cerezo, et al., 1996; Mash, et al., 1983; Oldershaw, et al., 1986) defiant child behavior. Thus, it was unclear whether the caregivers were giving more commands in response to child misbehavior. While Oldershaw and colleagues (1986) observed similar rates of child misbehavior during the observation as in the current study, caregivers in the abuse group had a significantly lower socioeconomic status than caregivers in the control group. While SES was a covariate in analyses, this important difference may account for differences in commands and why results of the current study differ from Oldershaw and colleagues (1986). In the study by Mash and colleagues (1983), mothers in the abuse group were significantly younger than mothers in the control group. The current study found that caregivers did not differ in their use of commands when required to exert moderate control on child behavior and when the children did not differ in noncompliance rate. Additionally, previous research had found that abusive caregivers do not give more commands than comparison caregivers in unstructured play situations (Bousha \& Twentyman, 1984; Wilson, et al., 2004), and the current study 
extended this finding of equivalence in use of commands to situations in which parents must exert moderate control.

The current study failed to replicate the findings of previous literature that abusive caregivers interact less frequently with their children (Burgess \& Conger, 1978; Bousha \& Twentyman, 1984; Lahey, et al., 1984). Indeed, results were in the opposite direction with abusive caregivers having significantly more total talk than comparison caregivers after controlling for child age, child gender, caregiver age, caregiver gender, race, caregiver education, and relation of parent to child. These results should be interpreted with caution because of potential differences in samples due to recruitment from different geographical regions. It is possible that residents of rural West Virginia are less talkative than residents of central Oklahoma. Additionally, given that abusive caregivers had been involved in parental fitness examinations in the past, they may have been more comfortable being observed, while the members of the comparison group may not have been observed interacting with their children in other situations. Alternatively, caregivers in the abuse group may have felt more apprehensive about being judged on their parenting skills because of their previous history with child physical abuse and talked more because they believed talking to children was more socially appropriate. Lastly, differences in materials available to the caregivers may have contributed to differences in total talk. Specifically, caregivers in the abuse group could choose from four to five activities while caregivers in the comparison group were only able to color with their children. It is possible that coloring elicits less talk from caregivers than other activities. Additionally, a number of differences in demographic variables between the groups were associated with total talk. Even though attempts were made to statistically 
control for these variables in analyses, they may have contributed to the findings in total talk in a manner different than hypothesized. Total talk was the only variable that differed based on caregiver race; specifically, Black/ African American caregivers had much higher total talk than Non-Hispanic, Caucasian caregivers. Even though race was controlled, given that all Black/ African American caregivers were in the abuse group, it is possible that differences due to more total talk in the abuse group may reflect cultural differences between racial groups rather than abusive and non-abusive caregivers. Additionally, male caregivers talked significantly more than female caregivers. Caregiver gender differences were only significant in the smaller sample which included children who were 4- and 5-years-old. However, regardless of the significance level, more caregivers in the abuse group were male which may have increased the heterogeneity of the sample, contributed to variability, and partially accounted for why caregivers in the abuse group had more total talk. These racial and gender differences between the groups, although statistically controlled, may account for the surprising results with total talk.

Caregiver gender and racial differences between the groups, while contributing to unwanted variability in this study, are important factors worthy of examination. None of the studies that have previously compared caregiver-child interactions between caregivers with and without prior reports of physical abuse have examined father-child interactions. Lack of examining father-child interactions is an important limitation of the previous literature, especially when considering that $35 \%$ of the caregivers included in Chaffin and colleagues' (2004) overall sample of caregivers were males. Father-child interactions have not been systematically studied in abusive samples, and the present study indicates 
that abusive fathers may interact differently with their children than either abusive mothers or nonabusive caregivers. Unfortunately, the present study, while controlling for caregiver gender, was unable to examine only fathers because of the few participating fathers in the comparison group. However, the evaluation of father-child interactions with regard to physically abusive populations is an important area for future research.

Additionally, racial differences in the make-up of groups and in total talk highlight the importance of cultural differences in caregiver-child interactions across different groups of people. The majority of the literature did not report the race or ethnicity of its participants. Of those that did (e.g., Bennett, et al., 2006; Borrego, et al., 2004; Wilson, et al., 2004), 33.3 to $69 \%$ of the abusive caregivers in their samples were African American. It is possible that caregiver-child interactions are characteristically different across cultural and ethnic groups and that results with one group do not generalize to caregiver-child interactions in other groups. It may be inappropriate to apply results obtained with one cultural or ethnic group to another group. This may be particularly relevant during parental fitness examinations in community settings.

A contribution of this study is that commands were compared in two samples with similar rates of child noncompliance during the observation. This allowed examination of parental use of commands without the confounding factor of child behavior differences between the groups. When considering the interactions as a whole, caregivers in both groups were similar with regard to commands and negative talk after controlling for total talk and demographic differences, but abusive caregivers provided significantly less praise. This may indicate that caregivers who have not been physically abusive provide more of a mix of statements to their children including more of a balance of praise with 
the commands and criticism. However, caregivers who have physically abused their children may not balance the commands and criticism with positive statements.

The findings from the current study highlight the importance of parental praise of the child and child's behavior. While caregivers in the comparison group gave relatively little praise, the caregivers in the abuse group gave almost no praise. This implies that it is a lack of positive appraisals of the child, or perhaps a lack of the caregiver recognizing positive child attributes and behavior, that is characteristic of caregivers who have physically abused their children. This may partially explain why parenting interventions that focus on increasing parental praise, as well as appropriate discipline strategies, have been successful in decreasing recidivism of reports of physical abuse (e.g., Chaffin, et al., 2004).

\section{Implications}

These findings have implications for parental fitness examinations in cases where child physical abuse is suspected. This study provides guidance for clinicians on which aspects of parent behavior during observations may be most relevant and suggests that lack of any type of praise may be most useful in identification of parents who have been physically abusive. However, for best practice, parent-child observations should be part of a broader multi-modal assessment that includes other assessment measures and multiple informants, if possible. Lack of praise, in and of itself, does not necessarily mean that a parent has been physically abusive. It should be noted that differences in praise may reflect "better parenting" and "worse parenting" rather than specifically to "abusive” and "non-abusive.” Indeed, giving less "positive feedback" has also been associated with social anxiety in children (Hummel \& Gross, 2001), but other studies 
have found that high parental control rather than low warmth may be a better predictor of child social anxiety (Rork \& Morris, 2009). In contrast, low parental warmth and positivity, rather than high control, may indicate child abuse. However, lack of positivity has also been associated with communication patterns between depressed fathers and mothers (Jacob \& Johnson, 2001). Within the context of an overall assessment that includes observation of parent-child interactions, praise may be the most salient factor associated with physical abuse but it may also be associated with other parent or family dysfunction, such as parental depression.

\section{Limitations}

This study was limited by drawing the groups from two separate studies with differing original purposes which resulted in some procedural and sample differences. The geographic regions from which the samples were drawn for the studies differed in racial diversity resulting in racial differences between the two groups. While analyses indicated that only total talk differed by caregiver race and both race and total talk were controlled in analyses, it is possible that differing racial and geographic backgrounds introduced variation into the study that could not be controlled. Additionally, the comparison group, being from West Virginia, may have been more rural than the abuse group in which participants were recruited from Oklahoma. Even though Bousha and Twentyman (1984) found similar results with an urban sample as did Burgess and Conger (1978) with a rural sample, the current study is limited because the two groups were not similar with regard to geography and this was not controlled in analyses.

Another difference in the procedures of the studies was that observations of caregivers in the abuse group took place in a clinic while observations of comparison 
caregivers took place in the home or local Head Start facility. These locations varied in familiarity to the families and may have presented different demand characteristics. For example, in the comparison group, the experimenter and video camera were in the room with the caregiver and child, while in the abuse group, observers and recording equipment were behind a one-way mirror. Thus, observation was more overt in the comparison group.

Also, data from the second 5-minute observation of the abusive caregivers were utilized, while data from the first 5-min “warm-up” condition of the comparison caregivers were used. The second 5-minute condition from the observations of the abusive caregivers was chosen because it best resembled the level of parental control required by the situation in the comparison condition. However, parent behavior may have differed between the groups because of the differing lengths of time that they had been observed and videotaped interacting with their children prior to the observation examined in the current study. Lastly, the comparison group had only crayons with which to play, while caregivers in the abuse group could choose from four to five toys (i.e., crayons, blocks, cars) and had the option to switch toys during the observation. It is possible that the wider variety of toys available to the abuse group introduced variation into the caregiver behaviors between groups which was not related to their abuse status. Also, coloring may elicit less parental talk than other types of activities. Racial and geographic differences, familiarity with and arrangements of the location, overall time of observation before the current situation, and materials available may also have contributed to more total talk in the abuse group than comparison group, which was a 
finding that contradicts previous literature (Burgess \& Conger, 1978; Bousha \& Twentyman, 1984; Lahey, et al., 1984), and limited the conclusions of this study.

Lastly, both groups may have been trying to present themselves in a socially desirable fashion. However, this may be especially true of caregivers in the abuse group because they were taking part in a study to improve their parenting skills because of a past history of child maltreatment. On the other hand, because of the parents' history of involvement with child protective services, they may have been relatively accustomed to being observed with their children. Caregivers in the comparison group participated in a study about parent behavior associated with child on-task behavior, which is a less threatening evaluation. However, they may not have had any history of being observed with their children and may have been more reactive to being videotaped interacting with their children. Thus, social desirability and reactivity to assessment may have impacted the results and limited the generalizability of the findings.

\section{Future Directions}

Future research should continue to include behavioral observations of caregiverchild interactions as a source of information to understand child physical abuse. Better understanding of what characterizes child physical abuse may benefit identification of abusive caregivers in parental fitness examinations and interventions to prevent further physical abuse. Additionally, research should be careful to consider demographic factors when examining caregiver-child interactions because demographic variables, such as race and caregiver gender, were associated with some variables of interest in the current study. These results indicate that caregiver-child interactions differ based on many factors that include but are not limited to whether the caregiver has physically abused a child. Also, 
there are potentially many variables beyond praise and those examined in this study that may be useful indicators of child physical abuse.

The current study found that male caregivers generally talked more and gave more commands than female caregivers. Yet no past research examining observed caregiver-child interactions in samples of physically abusive caregivers has focused on father-child interactions. Indeed, the vast majority of studies have only included mothers with reports of physical abuse. This is a significant limitation of the past literature especially because fathers, like mothers, can be physically abusive with their children. It is possible that results of studies examining the differences in caregiver-child interactions between abusive and non-abusive mothers do not generalize to how abusive and nonabusive fathers interact with their children. Future research should examine how fathers in general and fathers with a history of abuse in particular interact with their children.

Additionally, it is difficult to know whether differences in observed parenting behavior between abusive and non-abusive samples simply reflect differences in general parenting skill and family dysfunction. Future research should compare abusive parents with both clinically-referred parents and healthy comparison parents. Being able to distinguish abuse from other forms of family dysfunction would better inform clinical practice and parental fitness examinations. 


\section{References}

Abidin, R. R. (1995). Parenting Stress Index- Manual. ( ${ }^{\text {rd }}$ ed.). Odessa, FL; Psychological Assessment Resources, Inc.

Auslander, W. F., McMillen, J. C., Elze, D., Thompson, R., Jonson-Reid, M., \& Stiffman, A. (2002). Mental health problems and sexual abuse among adolescents in foster care: Relationship to HIV risk behaviors and intentions. AIDS and Behavior, 6, 351-359.

Baldwin, A.L., \& Ward, P. (1973, March). Computerized coding of observers' narration of interpersonal interaction. Paper presented at the meeting of the Society for Research in Child Development, Santa Monica, CA.

Belsky, J. (1993). Etiology of child maltreatment: A developmental-ecological analysis. Psychological Bulletin, 114, 413-434.

Bennett, D.S, Sullivan, M.W., \& Lewis, M. (2006). Relations of parental report and observation of parenting to maltreatment history. Child Maltreatment, 11, 63-75.

Borrego, J., Urquiza, A.J., Rasmussen, R.A., \& Zebell, N. (1999). Parent-child interaction therapy with a family at high risk for physical abuse. Child Maltreatment, 4, 331-342.

Borrego, J., Timmer, S.G., Urquiza, A.J., \& Follette, W.C. (2004). Physically abusive mothers' responses following episodes of child noncompliance and compliance. Journal of Consulting and Clinical Psychology, 72, 897-903.

Bousha, D.M. \& Twentyman, C.T. (1984). Mother-child interactional style in abuse, neglect, and control groups: Naturalistic observations in the home. Journal of Abnormal Psychology, 93, 106-114. 
Brent, D. A., Oquenda, M., Birmaher, B., Greenhill, L., Kolko, D., Stanley, B., Zelazny, J., Brodsky, B., Bridge, J., Ellis, S., Salazar, O., \& Mann, J. J. (2002). Familial pathways to early-onset suicide attempt: Risk for suicidal behavior in offspring of mood-disordered suicide attempters. Archives of General Psychiatry, 59, 801807.

Brestan, E.V., \& Eyberg, S.M. (1998). Effective psychosocial treatments of conductdisordered children and adolescents: 29 years, 82 studies, and 5,272 kids. Journal of Clinical Child Psychology, 27, 180-189.

Burgess, R.L. \& Conger, R.D. (1978). Family interaction in abusive, neglectful, and normal families. Child Development, 49, 1163-1173.

Cerezo, M.A. (1991). Interacciones familiares: Un sistema de evaluación observacional [Family interaction: A coding system for observational assessment.] Madrid, Spain, Mepsa.

Cerezo, M.A. (1997). Abusive family interaction: A review. Aggression and Violent Behavior, 2, 215-240.

Cerezo, M.A., D’Ocon, A., \& Dolz, L. (1996). Mother-child interactive patterns in abusive families versus nonabusive families: An observational study. Child Abuse and Neglect, 20, 573-587.

Cerezo, M.A., Keesler, R., Dunn, E.Y., \& Wahler, R.G. (1986). Standardized observation codes: SOC III. Unpublished document. Child Behavior Institute, University of Tennessee, USA. Spanish version published by Cerezo, M.A. (1991). Interacciones familiares: Un sistema de evaluación observacional [Family 
interaction: A coding system for observational assessment.] Madrid, Spain, Mepsa.

Chadwick Center for Children and Families. (2004). Closing the quality chasm in child abuse treatment: Identifying and disseminating best practices. San Diego, CA: Author.

Chaffin, M., Silvosky, J.F., Funderburk, B., Valle, L.A., Brestan, E.V., Balachova, T., Jackson, S., Lensgraf, J., \& Bonner, B.L. (2004). Parent-child interaction therapy with physically abusive parents: Efficacy for reducing future abuse reports. Journal of Consulting and Clinical Psychology, 72, 500-510.

Child Welfare Information Gateway, U.S. Department of Health \& Human Services, Administration on Children, Youth, and Families. (2008). What is child abuse and neglect? Factsheet. Retrieved October 4, 2009 from http://www.childwelfare.gov/pubs/factsheets/whatiscan.cfm.

Cohen, J.A., Mandarin, A.P., Murray, L.K., \& Gellman, R. (2006). Psychosocial interventions for maltreated and violence-exposed children. Journal of Social Issues, 62, 737-766.

Conners, C.K., Sitarenios, G., Parker, J.D., \& Epstein, J.N. (1998). The revised Conners’ Parent Rating Scale (CPRS-R): Factor structure, reliability, and criterion validity. Journal of Abnormal Psychology, 26, 257-268.

Dolz, L., Cerezo, M.A. \& Milner, J.S. (1997). Mother-child interactional patterns in high and low-risk mothers. Child Abuse and Neglect, 21, 1149-1158.

Eisenstadt, T.H., Eyberg, S. M., McNeil, C.B., Newcomb, K., \& Funderburk, B. (1993). 
Parent-child interaction therapy with behavior problem children: Relative effectiveness of two stages and overall treatment outcome. Journal of Clinical Child Psychology, 22, 42-51.

Eyberg, S.M. (1988). Parent-child interaction therapy: Integration of traditional and behavioral concerns. Child and Family Behavior Therapy, 10, 33-46.

Eyberg, S. M., \& Matarazzo, R. G. (1980). Training parents as therapists: A comparison between individual parent-child interaction training and parent group didactic training. Journal of Clinical Psychology, 36, 492-499.

Eyberg, S. M., \& Robinson, E. A. (1982). Parent-child interaction training: Effects on family functioning. Journal of Clinical Child Psychology, 11, 130-137.

Eyberg, S.M., Bessmer, J.L., Newcomb, K., Edwards, D., \& Robinson, E.A. (1994). Dyadic Parent-Child Coding System- II (DPICS- II). Corte Madera, CA: Select Press.

Eyberg, S.M., Nelson, M.M., Duke, M., \& Boggs, S.R. (2005). Manual for the dyadicchild interaction coding system ( $3^{\text {rd }}$ ed.). Retrieved October, 4, 2009 from www.pcit.org.

Fagot, B.I. (1984). A training manual for the Fagot (1984) Interactive Behavior Code. Unpublished manuscript. (Available from B.I. Fagot, Oregon Social Learning Center, Suite 202, 107 east Fifth Avenue, Eugene, OR 97401)

Fernandez, M.A., Chase, R.M., Ingalls, C.A., \& Eyberg, S.M. (2006). The Abridged Workbook: Coder Training Manual for the Dyadic Parent-Child Interaction Coding System ( $3^{\text {rd }}$ ed.). Retrieved October 20, 2009 from www.pcit.org.

Hakman, M., Chaffin, M., Funderburk, B., \& Silovsky, J. F. (2009). Change trajectories 
for parent-child interaction sequences during parent-child interaction therapy for child physical abuse. Child Abuse and Neglect, 33, 461-470.

Hood, K.K, \& Eyberg, S.M. (2003). Outcomes of parent-child interaction therapy: Mothers' reports of maintenance to six-years after treatment. Journal of Clinical Child and Adolescent Psychology, 32, 419-429.

Hummel, R. M., \& Gross, A. M. (2001). Socially anxious children: An observational study of parent-child interaction. Child and Family Behavior Therapy, 23, 19-40.

Jacobs, J.R., Boggs, S.R., Eyberg, S.M., Edwards, D.L., Durning, P., Querido, J.G., et al. (2000). Psychometric properties and reference point data for the revised edition of the school observation coding system. Behavior Therapy, 31, 695-712.

Jacob, T., \& Johnson, S. L. (2001). Sequential interactions in the parent-child communications of derpessed fathers and depressed mothers. Journal of Family Psychology, 15, 38-52.

Kaplan, S.J., Pelcovitz, D., Salzinger, S., Weiner, M., Mandel, F.S., Lesser, M.L., \& Labruna, V.E. (1998). Adolescent physical abuse: Risk for adolescent psychiatric disorders. American Journal of Psychiatry, 155, 954-959.

Kaplow, J.B., \& Widom, C.S. (2007). Age of onset of child maltreatment predicts longterm mental health outcomes. Journal of Abnormal Psychology, 116, 1, 176-187.

Kaufman, J. \& Cicchetti, D. (1989). Effects of maltreatment on school-age children’s socioemotional development: Assessments in a day-camp setting. Developmental Psychology, 25, 516-524.

Kavanagh, K.A., Youngblade, L., Reid, J.B., \& Fagot, B.I. (1988). Interactions between children and abusive versus control parents. Journal of Clinical Child Psychology, 
17, 137-142.

Knickerbocker, L., Heyman, R.E., Slep, A.M.S., Jouriles, E.N., \& McDonald, R. (2007). Co-occurrence of child and partner maltreatment: Definitions, prevalence, theory, and implications for assessment. European Psychologist, 21, 36-44.

Kunitz, S.J., Levy, J.E., McCloskey, J., \& Gabriel, K.R. (1998). Alcohol dependence and domestic violence as sequel of abuse and conduct disorder in childhood. Child Abuse and Neglect, 22, 1079-1091.

Lahey, B.B., Conger, R.D., Atkeson, B.M., \& Treiber, F.A. (1984). Parenting behavior and emotional status of physically abusive mothers. Journal of Consulting and Clinical Psychology, 52, 1062-1071.

Lundahl, B.W., Nimer, J., \& Parsons, B. (2006). Preventing child abuse: A meta-analysis of parent training programs. Research on Social Work Practice, 16, 251-262.

Mash, E.J., Johnston, C., \& Kovitz, K. (1983). A comparison of the mother-child interactions of physically abused and non-abused children during play and task situations. Journal of Clinical Child Psychology, 12, 337-346.

Mash, E.J., Terdal, L.G., \& Anderson, K. (1973). The response-class matrix: A procedure for recording parent-child interactions. Journal of Consulting and Clinical Psychology, 40, 163-164.

McCabe, K.M., Hough, R.L., Yeh, M., Lucchini, S.E., \& Hazen, A. (2005). The relation between violence exposure and conduct problems among adolescents: A prospective study. American Journal of Orthopsychiatry, 75, 4, 575-584.

Milner, J. S. (1986). The Child Abuse Potential Inventory Manual. (2 ${ }^{\text {nd }}$ ed.). DeKalb, IL: Psytec. 
Milner, J.S. \& Chilamkurti, C. (1991). Physical child abuse perpetrator characteristics: A review of the literature. Journal of Interpersonal Violence, 6, 345-366.

Min, M., Farkas, K., Minnes, S., \& Singer, L.T. (2007). Impact of childhood abuse and neglect on substance abuse and psychological distress in adulthood. Journal of Traumatic Stress, 20, 833-844.

Nixon, R.D.V. (2001). Changes in hyperactivity and temperament in behaviourally disturbed preschoolers after parent-child interaction therapy (PCIT). Behaviour Change, 18, 168-176.

Oldershaw, L., Walters, G.C., \& Hall, D.K. (1986). Control strategies and noncompliance in abusive mother-child dyads: An observational study. Child Development, 57, 722-732.

Reinherz, H. Z., Paradis, A. D., Giaconia, R. M., Stashwick, C. K., \& Fitzmaurice, G. (2003). Childhood and adolescent predictors of major depression in the transition to adulthood. American Journal of Psychiatry, 160, 2141-2147.

Robinson, E.A, \& Eyberg, S.M. (1981). The dyadic parent-child interaction coding system: Standardization and validation. Journal of Consulting and Clinical Psychology, 49, 245-250.

Rork, K. E., \& Morris, T. L. (2009). Influence of parenting factors on childhood social anxiety: Direct observation of parental warmth and control. Child \& Family Behavior Therapy, 31, 220- 235.

Schuhmann, E.M., Foote, R.C., Eyberg, S.M., Boggs, S.R., \& Algina, J. (1998). Efficacy of parent-child interaction therapy: Interim report of a randomized trial with short-term maintenance. Journal of Clinical Child Psychology, 27, 34-45. 
Tempel, A. B., Wagner, S., McNeil, C. B. (in press). Parent-child interaction therapy: The effects of parental attention components on children's verbalizations and attending-to-task behaviors. Manuscript accepted for publication.

Timmer, S.G., Urquiza, A.J., Zebell, N.M., \& McGrath, J.M. (2005). Parent-child interaction therapy: Application to maltreating parent-child dyads. Child Abuse and Neglect, 29, 825-842.

Valentino, K., Cicchetti, D., Toth, S.L., \& Rogosch, F.A. (2006). Mother-child play and emerging social behaviors among infants from maltreating families. Developmental Psychology, 42, 474-485.

Urquiza, A.J., \& McNeil, C.B. (1996). Parent-child interaction therapy: An intensive dyadic intervention for physically abusive families. Child Maltreatment, 1, 134144.

U.S. Department of Health and Human Services, Administration on Children, Youth and Families. (2009) Child Maltreatment 2007. Retrieved from http://www.acf.hhs.gov/programs/cb/pubs/cm07/cm07.pdf.

Webster-Stratton, C. (1985). Comparisons of behavior transactions between conductdisordered children and their mothers in the clinic and at home. Journal of Abnormal Child Psychology, 13, 169-183.

Webster-Stratton, C., \& Hammond, M. (1990). Predictors of treatment outcome in parent training for families with conduct problem children. Behavior Therapy, 21, 319337.

Wilson, S.R., Morgan, W.M., Hayes, J., Bylund, C., \& Herman, A. (2004). Mothers’ 
child abuse potential as a predictor of maternal and child behaviors during playtime interactions. Communication Monographs, 71, 395-421.

Wilson, S.R., Rack, J.J., Shi, X., \& Norris, A.M. (2008). Comparing physically abusive, neglectful, and non-maltreating parents during interactions with their children: A meta-analysis of observational studies. Child Abuse and Neglect, 32, 897-911.

Wilson, H.W. \& Widom, C.S. (2008). An examination of risky sexual behavior and HIV in victims of child abuse and neglect: A 30-year follow-up study. Health Psychology, 27, 149-158. 
Appendix: Dyadic Parent-Child Interaction Coding System 
Definitions, examples, and Cohen's kappa for the behavior categories of the DPICS used in this study

\begin{tabular}{|c|c|c|c|c|}
\hline $\begin{array}{l}\text { Behavior } \\
\text { Category }\end{array}$ & Definition & Example & $\begin{array}{c}\text { Brestan }^{1} \\
\text { Kappa }\end{array}$ & $\begin{array}{c}\text { Bessmer }^{2} \\
\text { Kappa }\end{array}$ \\
\hline $\begin{array}{l}\text { Parent Labeled } \\
\text { Praise }\end{array}$ & $\begin{array}{l}\text { A specific } \\
\text { statement of } \\
\text { approval and } \\
\text { teaches the } \\
\text { child what can } \\
\text { be done to } \\
\text { receive further } \\
\text { parental } \\
\text { approval }\end{array}$ & $\begin{array}{l}\text { "You did a } \\
\text { great job of } \\
\text { building the } \\
\text { tower." }\end{array}$ & .49 & .68 \\
\hline $\begin{array}{l}\text { Parent } \\
\text { Unlabeled } \\
\text { Praise }\end{array}$ & $\begin{array}{c}\text { A general } \\
\text { statement of } \\
\text { approval that } \\
\text { may not } \\
\text { reinforce } \\
\text { behavior but } \\
\text { may increase a } \\
\text { child's self } \\
\text { esteem }\end{array}$ & “Good job!” & .66 & .70 \\
\hline $\begin{array}{l}\text { Parent Critical } \\
\text { Statement/ } \\
\text { Negative Talk }\end{array}$ & $\begin{array}{c}\text { A verbal } \\
\text { expression of } \\
\text { disapproval and } \\
\text { includes sassy, } \\
\text { sarcastic, rude, } \\
\text { or impudent } \\
\text { comments }\end{array}$ & $\begin{array}{l}\text { "You're being } \\
\text { naughty” or } \\
\text { "Put it down or } \\
\text { else!” }\end{array}$ & .57 & .62 \\
\hline $\begin{array}{l}\text { Parent Direct } \\
\text { Command }\end{array}$ & $\begin{array}{l}\text { A statement } \\
\text { that contains an } \\
\text { order or } \\
\text { direction for a } \\
\text { behavior from } \\
\text { the child }\end{array}$ & "Listen." & .65 & .69 \\
\hline $\begin{array}{l}\text { Parent Indirect } \\
\text { Command }\end{array}$ & $\begin{array}{l}\text { A suggestion } \\
\text { for a behavior } \\
\text { from the child } \\
\text { that is implied } \\
\text { or in question } \\
\text { form }\end{array}$ & $\begin{array}{l}\text { "Let's build a } \\
\text { tower" or “Why } \\
\text { don’t you put } \\
\text { your hands in } \\
\text { your lap.” }\end{array}$ & .64 & .63 \\
\hline $\begin{array}{c}\text { Child } \\
\text { Compliance }\end{array}$ & $\begin{array}{l}\text { Child performs, } \\
\text { begins to } \\
\text { perform, or } \\
\text { attempts to } \\
\text { perform a task }\end{array}$ & & .69 & .71 \\
\hline
\end{tabular}


requested by

parent within 5

seconds

Note: Definitions and examples from Eyberg, et al., 2005, p. 46-136

${ }^{1}$ Kappa from Brestan, Foote, \& Eyberg, 2005, in Eyberg, et al., 2005, p. 225-226

${ }^{2}$ Kappa from Bessmer, Brestan, \& Eyberg, 2005, in Eyberg, et al., 2005, p. 225-226

${ }^{3}$ Parent Critical Statements from DPICS-II became Negative Talk in DPICS-III 
Table 1

Demographic Variables and Child Noncompliance Between the Groups (70 Dyads)

\begin{tabular}{|c|c|c|}
\hline Variable & Abuse $(\mathrm{N}=39)$ & Nonabuse $(\mathrm{N}=31)$ \\
\hline Caregiver Age & $29.31(7.91)$ & $31.16(7.54)$ \\
\hline Caregivers’ Gender (\% Female) & 71.8 & 93.5 \\
\hline \multicolumn{3}{|l|}{ Caregiver’s Race* (\%) } \\
\hline Caucasian & 53.8 & 93.5 \\
\hline African American & 33.3 & 0 \\
\hline Hispanic/ Latino & 5.1 & 0 \\
\hline Other (American Indian, Asian) & 5.1 & 6.5 \\
\hline \multicolumn{3}{|l|}{ Relation of Parent to Child (\%) } \\
\hline Biological Mother & 66.7 & 90.3 \\
\hline Biological Father & 12.8 & 6.5 \\
\hline Step Mom & 5.1 & 0 \\
\hline Step Dad & 2.6 & 0 \\
\hline Grandmother & 2.6 & 0 \\
\hline Great Grandmother & 10.3 & 3.2 \\
\hline \multicolumn{3}{|l|}{ Marital Status (\%) } \\
\hline Married or Living Together & 46.2 & 64.5 \\
\hline Divorced or Separated & 25.6 & 9.7 \\
\hline Never Married & 25.6 & 22.6 \\
\hline \multicolumn{3}{|l|}{ Caregiver’s Highest Level of Education (\%) } \\
\hline Less than $9^{\text {th }}$ Grade & 5.1 & 9.7 \\
\hline Less than $12^{\text {th }}$ Grade & 17.9 & 22.6 \\
\hline High School Diploma or GED & 43.6 & 41.9 \\
\hline Some College, Technical School, or 2-Year & 33.3 & 12.9 \\
\hline \multicolumn{3}{|l|}{ Degree } \\
\hline 4-year Degree & 0 & 9.7 \\
\hline More than a 4-year degree & 0 & 3.2 \\
\hline Child's Age* & $5.64(1.01)$ & $4.13(.76)$ \\
\hline Child’s Gender (\% Male) & 59.0 & 61.3 \\
\hline Child's Noncompliance Rate & $.08(.17)$ & $.15(.23)$ \\
\hline
\end{tabular}

* Significantly Different 
Table 2

Frequency of Variables of Interest

\begin{tabular}{|c|c|c|c|c|c|c|}
\hline Behavior & $\begin{array}{l}\text { Abuse Freq } \\
\quad(S D)\end{array}$ & $\begin{array}{l}\text { NonAbuse } \\
\text { Freq }(S D)\end{array}$ & F & $\begin{array}{c}\text { Partial Eta } \\
\text { Squared }\end{array}$ & $\begin{array}{c}\text { Abuse } \\
\text { Proportion of } \\
\text { Total }(S D)\end{array}$ & $\begin{array}{c}\text { NonAbuse } \\
\text { Proportion } \\
\text { of Total } \\
(S D)\end{array}$ \\
\hline Total Talk & 84.57 (26.32) & 48.84 (21.78) & $25.75^{* *}$ & .29 & & \\
\hline Praise & $1.29(2.51)$ & $4.1(3.82)$ & $13.66^{*}$ & .17 & $.01(.02)$ & $.08(.07)$ \\
\hline Commands & $18.74(13.40)$ & $10.42(8.66)$ & .001 & .00 & $.21(.10)$ & $.22(.16)$ \\
\hline $\begin{array}{l}\text { Negative } \\
\text { Talk }\end{array}$ & 4.87 (3.90) & 2.87 (5.93) & .07 & .00 & $.06(.04)$ & $.04(.08)$ \\
\hline
\end{tabular}


Table 3

Descriptive Statistics of Continuous Variables in Logistic Regression (70 Dyads)

\begin{tabular}{lccccc}
\hline Variable & $M$ & $S D$ & Min & Max & Skew \\
\hline Child Age & 4.97 & 1.18 & 3 & 7 & .17 \\
Total Talk & 68.49 & 29.93 & 9 & 151 & .30 \\
Total Praise & 2.51 & 3.43 & 0 & 15 & 1.76 \\
Total Commands & 14.86 & 12.14 & 0 & 60 & 1.73 \\
Negative Talk & 4.01 & 4.96 & 0 & 23 & 1.77 \\
\hline
\end{tabular}


Table 4

Correlations Among Variables in the Logistic Regression (70 Dyads)

\begin{tabular}{|c|c|c|c|c|c|}
\hline & 1 & 2 & 3 & 4 & 5 \\
\hline \multicolumn{6}{|l|}{ 1. Child Age } \\
\hline 2. Caregiver Race ${ }^{1}$ & $.24^{*}$ & & & & \\
\hline 3. Total Talk & $.24 *$ & $.37 * *$ & & & \\
\hline 4. Total Praise & $-.48 * *$ & -.21 & .12 & & \\
\hline 5. Total Commands & .04 & $.26^{*}$ & $.67 * *$ & .10 & \\
\hline 6. Negative Talk & -.03 & -.02 & $.50 * *$ & $.30 *$ & $.34 * *$ \\
\hline
\end{tabular}

$* p<.05, * * p<.01$

${ }^{1} 1$ = Caucasian, 2 = Non-Caucasian 
Table 5

Results of Logistic Regression Predicting Membership in Abuse Group (70 Dyads)

\begin{tabular}{lcccc}
\hline & & & \multicolumn{2}{c}{$95 \%$ Confidence Interval } \\
& Wald & Exp (B) & Lower & Upper \\
\hline Step 1 & & & & \\
- Child Age & $5.14^{*}$ & 115.20 & 1.91 & $6,965.41$ \\
- Caregiver Race & .18 & 1.95 & .09 & 41.31 \\
- Total Talk & $4.0^{*}$ & 1.19 & 1.00 & 1.40 \\
Step 2 & & & & .95 \\
- Total Praise & $4.18^{*}$ & .32 & .11 & 1.34 \\
- Total Commands & 1.62 & 1.12 & .94 & 2.47 \\
\hline
\end{tabular}

$$
* p<.05
$$


Table 6

Demographic Variables and Child Noncompliance Between the Groups (41 Dyads)

\begin{tabular}{|c|c|c|}
\hline Variable & Abuse $(\mathrm{N}=17)$ & NonAbuse $(\mathrm{N}=24)$ \\
\hline Caregiver Age & $30.00(9.77)$ & $32.46(7.86)$ \\
\hline Caregivers’ Gender* (\% Female) & 52.9 & 91.7 \\
\hline \multicolumn{3}{|l|}{ Caregiver’s Race* (\%) } \\
\hline Caucasian & 58.8 & 91.7 \\
\hline African American & 35.3 & 0 \\
\hline Hispanic/ Latino & 0 & 0 \\
\hline Other (American Indian, Asian) & 5.9 & 8.3 \\
\hline \multicolumn{3}{|l|}{ Relation of Parent to Child (\%) } \\
\hline Biological Mother & 64.7 & 87.5 \\
\hline Biological Father & 17.6 & 8.3 \\
\hline Step Dad & 5.9 & 0 \\
\hline Grandmother & 5.9 & 0 \\
\hline Great Grandmother & 5.9 & 4.2 \\
\hline \multicolumn{3}{|l|}{ Marital Status (\%) } \\
\hline Married or Living Together & 52.9 & 70.8 \\
\hline Divorced or Separated & 23.5 & 12.5 \\
\hline Never Married & 17.6 & 16.7 \\
\hline \multicolumn{3}{|l|}{ Caregiver’s Highest Level of Education (\%) } \\
\hline Less than $9^{\text {th }}$ Grade & 0 & 8.3 \\
\hline Less than $12^{\text {th }}$ Grade & 17.6 & 16.7 \\
\hline High School Diploma or GED & 47.1 & 45.8 \\
\hline $\begin{array}{l}\text { Some College, Technical School, or 2- } \\
\text { year Degree }\end{array}$ & 35.2 & 12.5 \\
\hline 4-year Degree & 0 & 12.5 \\
\hline More than a 4-year degree & 0 & 4.2 \\
\hline Child's Age & $4.65(.49)$ & $4.46(.51)$ \\
\hline Child’s Gender (\% Male) & 47.1 & 66.7 \\
\hline Child's Noncompliance Rate & $.11(.24)$ & $.16(.26)$ \\
\hline
\end{tabular}

* Significantly Different 
Table 7

Frequency of Variables of Interest with Sample Including only 4- and 5-year-olds

\begin{tabular}{|c|c|c|c|c|c|c|}
\hline Behavior & $\begin{array}{c}\text { Abuse Freq } \\
(S D)\end{array}$ & $\begin{array}{l}\text { NonAbuse } \\
\text { Freq }(S D)\end{array}$ & $\mathrm{F}$ & $\begin{array}{l}\text { Partial Eta } \\
\text { Squared }\end{array}$ & $\begin{array}{c}\text { Abuse } \\
\text { Proportion } \\
\text { of Total } \\
(S D)\end{array}$ & $\begin{array}{c}\text { NonAbuse } \\
\text { Proportion } \\
\text { of Total } \\
(S D)\end{array}$ \\
\hline Total Talk & $83.88(30.11)$ & $\begin{array}{c}44.04 \\
(21.83)\end{array}$ & $14.40 * *$ & .29 & & \\
\hline Praise & $1.88(3.40)$ & 3.00 (3.35) & $9.16^{*}$ & .20 & $.02(.03)$ & $.07(.08)$ \\
\hline Commands & $19.13(13.40)$ & 8.63 (7.89) & .01 & .01 & $.22(.11)$ & $.21(.15)$ \\
\hline $\begin{array}{l}\text { Negative } \\
\text { Talk }\end{array}$ & $5.38(4.15)$ & $1.88(4.16)$ & .16 & .00 & $.06(.04)$ & $.03(.06)$ \\
\hline
\end{tabular}


Table 8

Descriptive Statistics of Continuous Variables in Logistic Regression (41 Dyads)

\begin{tabular}{lccccc}
\hline Variable & $M$ & $S D$ & Min & Max & Skew \\
\hline Total Talk & 60.85 & 32.04 & 9 & 136 & .53 \\
Total Praise & 2.54 & 3.33 & 0 & 15 & 2.21 \\
Total Commands & 12.76 & 11.39 & 0 & 60 & 2.08 \\
Negative Talk & 3.29 & 4.40 & 0 & 17 & 1.75 \\
\hline
\end{tabular}


Table 9

Correlations Among Variables in the Logistic Regressions (41 Dyads)

\begin{tabular}{|c|c|c|c|c|c|}
\hline & 1. & 2. & 3. & 4. & 5. \\
\hline \multicolumn{6}{|l|}{ 1. Caregiver Gender } \\
\hline 2. Caregiver Race ${ }^{1}$ & -.22 & & & & \\
\hline 3. Total Talk & $-.38 *$ & .30 & & & \\
\hline 4. Total Praise & -.22 & -.21 & .24 & & \\
\hline 5. Total Commands & $-.47 * *$ & .22 & $.65^{* *}$ & .14 & \\
\hline 6. Total Negative Talk & -.05 & -.02 & $.60 * *$ & .30 & $.33 *$ \\
\hline
\end{tabular}

${ }^{*} \mathrm{p}<.05,{ }^{* *} \mathrm{p}<.01,{ }^{1} 1$ = Caucasian, 2 = Non-Caucasian 
Table 10

Results of Logistic Regression Predicting Membership in Abuse Group (41 Dyads)

\begin{tabular}{lcccc}
\hline & & & \multicolumn{2}{c}{$95 \%$ Confidence Interval } \\
& Wald & Exp (B) & Lower & Upper \\
\hline Step 1 & & & & \\
- Caregiver Gender & 2.82 & .10 & .01 & 1.47 \\
- Total Talk & $4.71^{*}$ & 1.10 & 1.01 & 1.19 \\
Step 2 & & & & \\
- Total Praise & & & .24 & .87 \\
- Total Commands & $5.60^{*}$ & .45 & .87 & 1.19 \\
- Negative Talk & .04 & 1.02 & .92 & 2.07 \\
\hline
\end{tabular}

$* p<.05$ 
Table 11

Results of Logistic Regression Predicting Membership in Abuse Group including Race (41

Dyads)

95\% Confidence Interval

Wald

$\operatorname{Exp}(\mathrm{B})$

Lower

Upper

Step 1

- Caregiver Gender

2.70

.10

.01

1.57

- Caregiver Race

.25

2.09

.12

37.29

- Total Talk

4.52*

1.10

1.01

1.19

Step 2

- Total Praise

$5.08 *$

.47

.25

.91

- Total Commands

.00

1.00

.85

1.18

- Negative Talk

2.65

1.40

.93

2.11

$* p<.05$ 
Table 12

Differences Between Caregivers who Identified as Different Races

\begin{tabular}{lccccc}
\hline Behavior & $\begin{array}{c}\text { Caucasian/ Not } \\
\text { Hispanic }\end{array}$ & $\begin{array}{c}\text { African } \\
\text { American }\end{array}$ & Hispanic & Other & F \\
& $M(S D)$ & $M(S D)$ & $M(S D)$ & $M(S D)$ & \\
\hline Child Age & $4.78(1.18)$ & $5.46(1.05)$ & $6.0(.00)$ & $5.0(1.41)$ & 1.74 \\
Total Talk & $61.64(28.67)$ & $89.75(30.00)$ & $75.50(4.95)$ & $83.25 .(24.14)$ & $3.59 *$ \\
Praise & $3.00(3.80)$ & $1.69(2.06)$ & $1.0(1.41)$ & $.50(1.0)$ & 1.17 \\
Commands & $12.66(10.96)$ & $20.38(15.54)$ & $15.50(10.61)$ & $19.50(8.50)$ & 1.71 \\
Negative Talk & $4.04(5.35)$ & $4.77(4.49)$ & $2.50(.71)$ & $1.50(1.91)$ & .49 \\
\hline$* p<.05$ & & & &
\end{tabular}

